\title{
Torsional stability of interference screws derived from bovine bone - a biomechanical study
}

\author{
Joscha Bauer ${ }^{\dagger 1}$, Turgay Efe ${ }^{*+1}$, Silke Herdrich² ${ }^{2}$ Leo Gotzen ${ }^{3}$, Bilal Farouk El-Zayat ${ }^{1}$, Jan Schmitt ${ }^{1}$, Nina Timmesfeld ${ }^{4}$ and \\ Markus Dietmar Schofer ${ }^{1}$
}

\begin{abstract}
Background: In the present biomechanical study, the torsional stability of different interference screws, made of bovine bone, was tested. Interference screws derived from bovine bone are a possible biological alternative to conventional metallic or bioabsorbable polymer interference screws.

Methods: In the first part of the study we compared the torsional stability of self-made $8 \mathrm{~mm}$ Interference screws (BC) and a commercial $8 \mathrm{~mm}$ interference screw (Tutofix ${ }^{\circ}$ ). Furthermore, we compared the torsional strength of BC screws with different diameters. For screwing in, a hexagon head and an octagon head were tested. Maximum breaking torques in polymethyl methacrylate resin were recorded by means of an electronic torque screw driver. In the second part of the study the tibial part of a bone-patellar tendon-bone graft was fixed in porcine test specimens using an 8 $\mathrm{mm} \mathrm{BC}$ screw and the maximum insertion torques were recorded. Each interference screw type was tested 5 times.

Results: There was no statistically significant difference between the different $8 \mathrm{~mm}$ interference screws $(p=0.121)$. Pairwise comparisons did not reveal statistically significant differences, either. It was demonstrated for the BC screws, that a larger screw diameter significantly leads to higher torsional stability $\left(p=9.779 \times 10^{-5}\right)$. Pairwise comparisons showed a significantly lower torsional stability for the $7 \mathrm{~mm} \mathrm{BC}$ screw than for the $8 \mathrm{~mm} \mathrm{BC} \mathrm{screw}(p=0.0079)$ and the $9 \mathrm{~mm} \mathrm{BC}$ screw $(p=0.0079)$. Statistically significant differences between the $8 \mathrm{~mm}$ and the $9 \mathrm{~mm} \mathrm{BC}$ screw could not be found $(p=0.15)$. During screwing into the tibial graft channel of the porcine specimens, insertion torques between $0.5 \mathrm{Nm}$ and $3.2 \mathrm{Nm}$ were recorded. In one case the hexagon head of $\mathbf{a}$ BC screw broke off during the last turn.

Conclusions: The BC screws show comparable torsional stability to Tutofix interference screws. As expected the torsional strength of the screws increases significantly with the diameter. The safety and in vivo performance of products derived from xenogeneic bone should be the focus of further investigations.
\end{abstract}

\section{Background}

The continuous increase in recreational sports leads to a continuously increasing number of capsule and ligament injuries of the knee joint as well. About $20 \%$ of the knee injuries are accompanied by anterior cruciate ligament (ACL) ruptures [1]. Every year, about 35,000 ACL ruptures occur in Germany, of which about 28,000 (80\%) are treated surgically [2]. The reconstruction of the ACL belongs to the therapies of choice for the active patient and is one of most common ligament reconstructions in the knee [3]. Together with the semitendinosus and graci-

*Correspondence: efet@med.uni-marburg.de

1 Department of Orthopaedics and Rheumatology, University Hospital

Marburg, Baldingerstrasse, 35043 Marburg, Germany

+ Contributed equally

Full list of author information is available at the end of the article lis tendon, the central part of the patellar tendon with adjacent bone blocks has been proven to be a suitable transplant with high failure load and sufficient osteointegration $[4,5]$. The secure fixation of the transplant is required for the restoration of knee stability and early functional rehabilitation [6]. Thereby the tibial transplant fixation is of particular importance. The tibial fixation devices must resist higher shear forces applied parallel to the axis of the tibial drill channel $[7,8]$ that has a lower bone density compared to the femur $[9,10]$. Laxdal et al. [11] showed that pull out of the tibial graft fixation was the most common reason for transplant failure in the early phase of rehabilitation.

Different methods of bone-patellar tendon-bone (BPTB) graft fixation are commercially available. The most com- 
mon method for BPTB graft fixation is interference screw fixation [12]. Interference screws made of metal or absorbable polymers are available $[4,13]$ and have specific advantages and disadvantages. Metal screws are implanted permanently and can lead to complications at the implant site or have to be removed sometimes in a second operation - which can be difficult and time consuming [14]. Additionally, metal implants cause artefacts in MRI examinations and thus may complicate further diagnostics. In the case of bioabsorbable polymer screws the degradation process is still a problem [15] and the course of degradation is highly variable $[16,17]$. Screws made of bioabsorbable materials can break at high torque during implantation [18]. Broken screws are difficult to adjust or to remove, if they are not positioned ideally when breakage occurs. Screw fragments can impair the graft and cause intraarticular damage [19,20].

Interference screws derived from bovine compact bone are a biological alternative to conventional materials [21]. The clinical application of bovine cancellous bone as bone graft or implant in orodental surgery has already been reported [22,23]. Ideally, xenogeneic materials are firmly incorporated into the bone and are substituted over the course of time by autologous bone [23]. In previous studies, the maximum failure load [24-31] and the torsional stability $[18,30,32-34]$ of interference screws have been investigated. In these studies, screws derived from xenogeneic material did not get much attention. To our knowledge, there is no biomechanical study so far regarding the torsional strength of xenogeneic interference screws.

In the first part of the study we evaluated the biomechanical properties of self-made interference screws (BC) as well as an industrial produced interference screw (Tutofix ${ }^{\circ}$ ) in polymethyl methacrylate resin. The aim of this part of the study was to provide data for maximum breaking torques of the $8 \mathrm{~mm} \mathrm{BC}$ and $8 \mathrm{~mm}$ Tutofix interference screws and compare them with the results of bioabsorbable polymer screws provided in the literature. Furthermore, we provided data for maximum breaking torques of $\mathrm{BC}$ screws with different diameters. We hypothesised that the maximum breaking torques of the different $8 \mathrm{~mm}$ interference screws differ significantly and that a larger diameter significantly correlates with a higher maximum breaking torque. In the second part of the study we investigated the biomechanical properties of the $8 \mathrm{~mm} \mathrm{BC}$ screw in a porcine tibia. The aim of this part of the study was to provide data for the insertion torque and compare with the results of bioabsorbable polymer screws provided in the literature. There is little data on bovine interference screws. Testing their mechanical properties with two different methods seems to be appropriate to evaluate their value in a possible clinical setup.

\section{Methods}

Interference screws derived from bovine bone were tested. At the beginning of the investigation, commercial screws of bovine bone were only available with a diameter of $8 \mathrm{~mm}$. The limited availability forced us to produce screws with diameters of $7 \mathrm{~mm}, 8 \mathrm{~mm}$ and $9 \mathrm{~mm}$. Five specimens of each type of interference screw were tested. All experiments were carried out by the same person to minimise differences in the test performance.

\section{Interference screws}

The $\mathrm{BC}$ interference screws were produced from cortical bone of bovine tibial diaphyses by the department of precision mechanics of our institution (Fig. 1). Longish segments of $7 \times 30 \mathrm{~mm}, 8 \times 30 \mathrm{~mm}$ and $9 \times 30 \mathrm{~mm}$ were cut out of the cleaned bone shafts and cylindrically turned on a lathe (Hommels-Herkules, EBK 450, Viernheim, Germany). Subsequently the screw thread was cut (thread depth $1 \mathrm{~mm}$, thread infeed $2.5 \mathrm{~mm}$ per turn). The noncannulated screws had a hexagonal drive head. The elongated thread free tip was intended to ensure a target-oriented implantation without a guide wire. The $8 \mathrm{~mm} \mathrm{BC}$ screw was also tested with an octagonal drive head. In pre-test other insertion devices had shown to be unstable and not feasible. As the screws did not have a full thread, the thread length was $19 \mathrm{~mm}$. After completion, the screws were treated in a $99 \%$ acetone bath to extract lipids, to kill microorganisms and to reduce the antigenic properties. The screws were autoclaved at $121^{\circ} \mathrm{C}$ and 3 bar steam pressure for $20 \mathrm{~min}$ and stored at room temperature in a dry place until they were used. The $8 \times 21$ mm Tutofix screw (Tutogen, Neunkirchen am Brand, Germany) had a thread length of $18 \mathrm{~mm}$, a thread depth of $0.7 \mathrm{~mm}$, a thread infeed of $2.1 \mathrm{~mm}$ per turn and a hexagonal drive head. The screws were processed according to the Tutoplast process. The Tutoplast process is a vali-

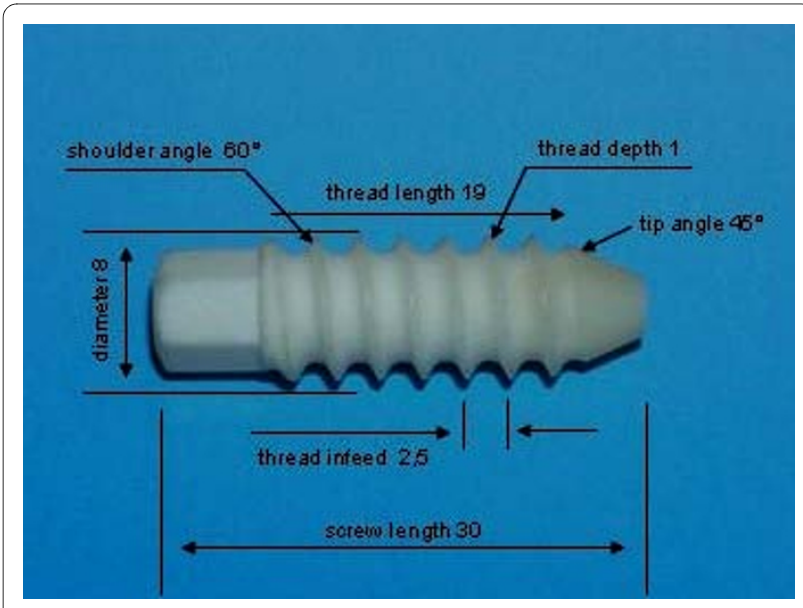

Figure 1 Design specification of the $8 \mathrm{~mm} \mathrm{BC}$ interference screw with hexagon head. 
dated bone sterilisation method and is certified for bovine bone. Biocompatibility and biomechanical integrity have been demonstrated [35-37].

\section{Torsional stability in polymethyl methacrylate}

24 hours before testing, the screws were embedded into a $20 \mathrm{~mm}$ layer of polymethyl methacrylate resin (Heraeus, Technovit 9100, Wehrheim, Germany). The screws protruded $10 \mathrm{~mm}$ from the resin surface (Fig. 2) to simulate a worst-case situation in vivo, in which the screws jam during screwing in at the graft channel. For each type of screw, a custom-made adapter (Fig. 3) was used, which was mounted onto the electronic torque screw driver (Totti, DTDK-N50 E, Wuppertal, Germany). The screw driver was calibrated from $0.5 \mathrm{Nm}$ to $5 \mathrm{Nm}$ and had a measuring accuracy of $0.005 \mathrm{Nm}$. On the day of the experiment, the polymethyl methacrylate resin with the embedded screws was firmly clamped into a holder. The screws were slowly turned manually under a constant axial loading until screw breakage occurred. Maximum breaking torque was recorded for each screw.

\section{Torsional stability with porcine knee specimen}

Porcine specimen (age 12-14 month) were supplied by the local slaughterhouse on the day of slaughter and then frozen at $-20^{\circ} \mathrm{C}$. Prior to the experiments the test specimen were thawed slowly for 13 hours at room temperature. A $10 \mathrm{~mm}$ BPTB graft was obtained according to standard procedure and the tibial bone plug was cut to 25 $\times 10 \times 7 \mathrm{~mm}$. Using a cruciate ligament targeting device (Synthes, Umkirch, Germany), a Kirschner wire was applied and the graft channel was reamed to $10 \mathrm{~mm}$. The angle between the drill channels and the tibial long axis was $50^{\circ}$. A thread was cut into the drill channel and the grafts fixed with an $8 \mathrm{~mm} \mathrm{BC}$ screw (hexagon head) under a pretension of 60 Newton $(\mathrm{N})$. The screws were

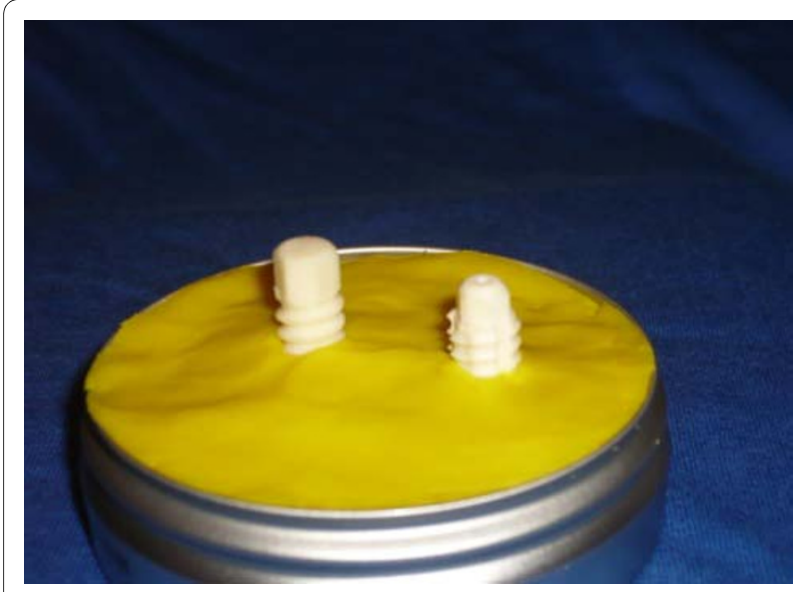

Figure 2 Interference screws derived from bovine bone in polymethyl methacrylate, left BC screw, right Tutofix screw.

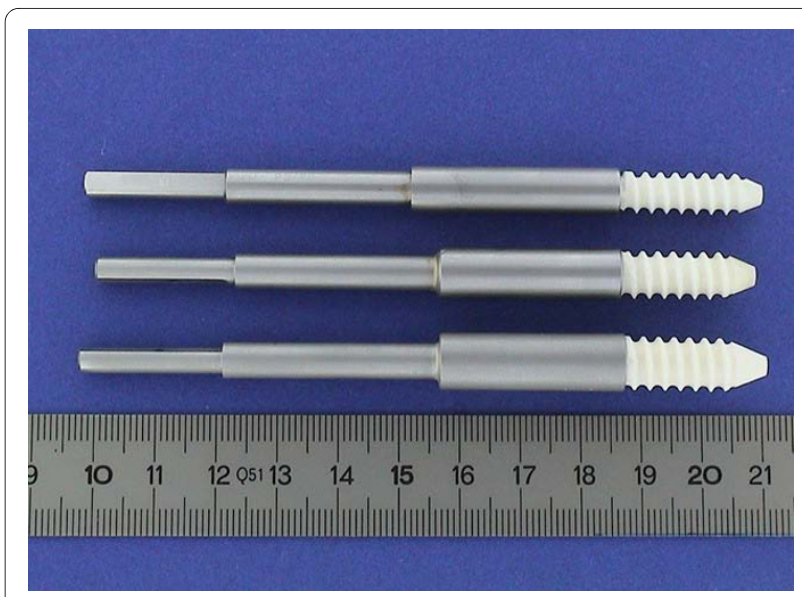

Figure $37 \mathrm{~mm}, 8 \mathrm{~mm}$ and $9 \mathrm{~mm} \mathrm{BC}$ interference screws with screw driver adapter.

placed directly below the articular surface always at the same relative position between the graft and the tunnel. Insertion torques were recorded with an electronic torque screw driver (Totti, DTDK-N50 E, Wuppertal, Germany).

\section{Statistical analysis}

Descriptive analysis was performed by determination of mean values, standard deviations, minimum and maximum values. To investigate the difference between the three $8 \mathrm{~mm}$ screws, a non-parametric analysis of variance (Kruskal-Wallis test) was performed. To analyse the association between diameter and breaking torque, the Jonckheere-Terpstra test for trend was performed. All pairwise comparisons were done by the Wilcoxon rank-sum test. The significance level was set to $\mathrm{P}<0.05$.

\section{Results}

Regarding the torsional stability, there was no statistically significant difference between the three types of $8 \mathrm{~mm}$ interference screws $(p=0.121)$. Fig. 4 shows the pairwise comparison of the three different $8 \mathrm{~mm}$ interference screws. A larger screw diameter significantly corresponded with an increasing torsional stability $(\mathrm{p}=9.779$ $\times 10^{-5}$ ). Fig. 5 shows the pairwise comparison of three different screw diameters. At the graft channel, the mean insertion torque was $0.58 \pm 0.08 \mathrm{Nm}$ at the beginning of screwing in. At the last turn until complete screw implantation, the mean insertion torque was $3.0 \pm 0.33 \mathrm{Nm}$. During the final rotation the maximum value was 3.31 $\mathrm{Nm}$, the minimum value was $2.50 \mathrm{Nm}$. One hexagonal head broke off during the last turn of screwing in at 3.20 $\mathrm{Nm}$. 


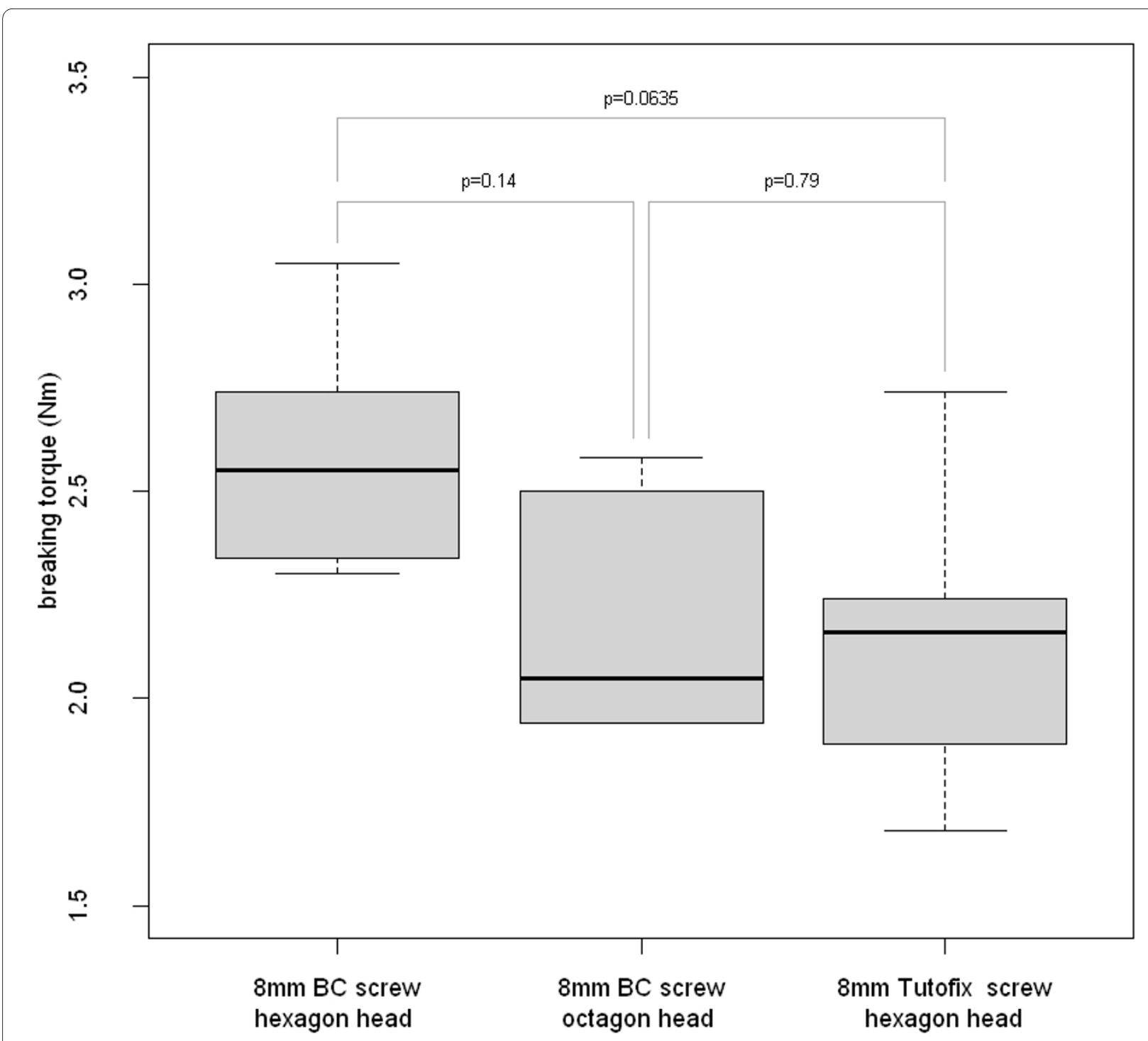

Figure 4 Pairwise comparison of the maximum breaking torques of three different $8 \mathrm{~mm}$ interference screws in polymethyl methacrylate resin and $\mathbf{p}$-values (Kruskal-Wallis test). There are no statistically significant differences between the three tested screw types

\section{Discussion}

The results of the present study partly confirmed the hypotheses postulated in the beginning. It could not be confirmed that the torsional stabilities of the three different $8 \mathrm{~mm}$ interference screws differ significantly. It was demonstrated for the different $\mathrm{BC}$ screws that a larger screw diameter leads to higher torsional stability. Pairwise comparisons confirmed the hypothesis that the torsional stability of the $7 \mathrm{~mm} \mathrm{BC}$ screw was lower than that of the $8 \mathrm{~mm} \mathrm{BC}$ screw and the $9 \mathrm{~mm} \mathrm{BC}$ screw. The postulated hypothesis regarding the pairwise comparison between $8 \mathrm{~mm}$ and $9 \mathrm{~mm} \mathrm{BC}$ screw could not be confirmed.
The biomechanical properties of interference screws made of metal and bioabsorbable polymer materials have been featured in numerous experimental studies which focussed mainly on pull-out testing [26,38-42]. Only a limited number of studies dealt with torsional stability of interference screw. Costi et al. [32] tested the torsional stability of 5 different bioabsorbable interference screws. Half the length of the $20 \mathrm{~mm}$ screws was embedded in polyurethane resin. The screws were turned manually with an electronic screw driver until failure occurred. The mean failure torque was between $1.07 \pm 0.18 \mathrm{Nm}(7$ $\mathrm{mm}$ poly-(glycolide-co-trimethylene carbonate)) and $5.23 \pm 0.24 \mathrm{Nm}(8 \mathrm{~mm}$ poly-(D, L-lactide) $)$. Furthermore, 


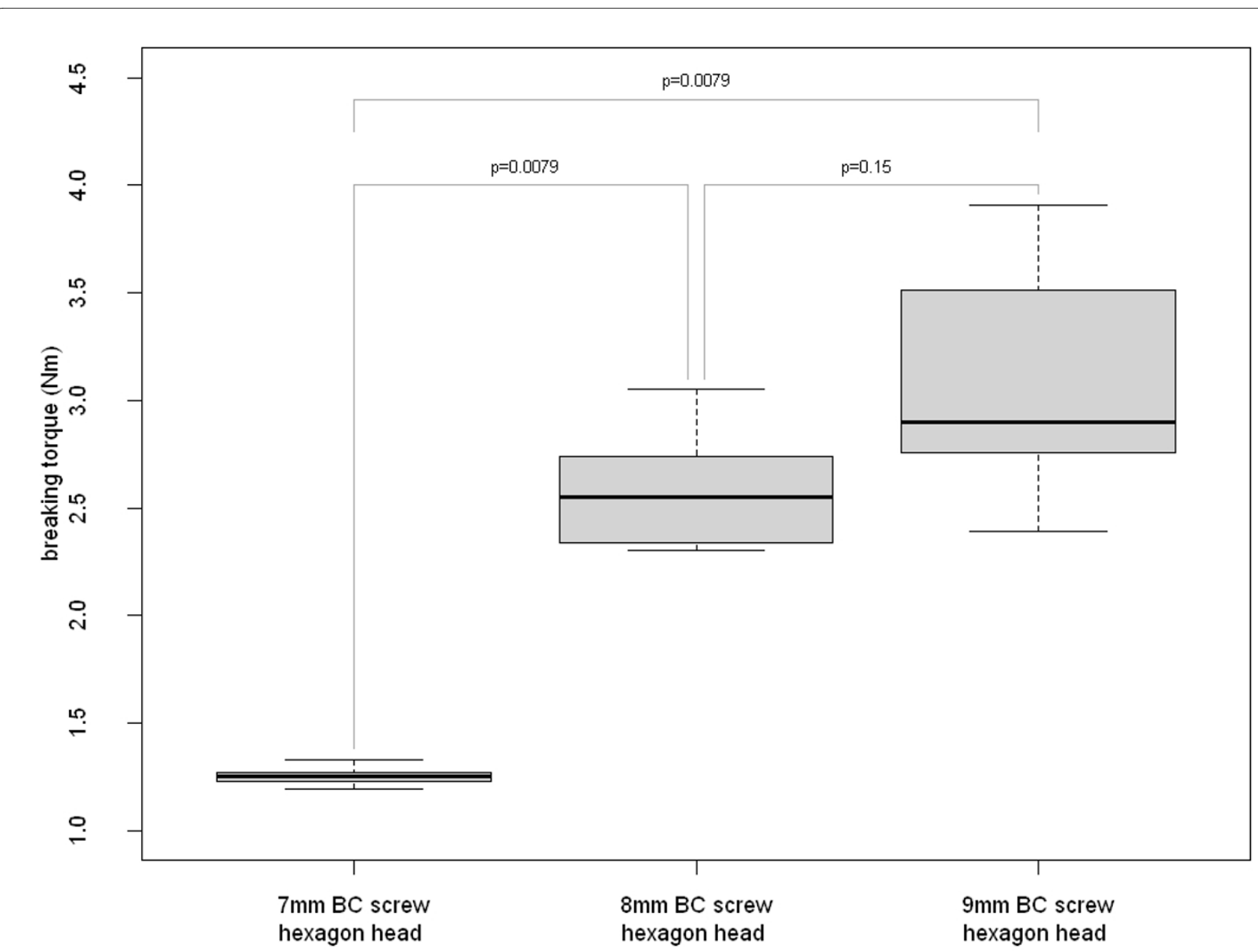

Figure 5 Pairwise comparison of the effect of the screw diameter on maximum breaking torques of $\mathrm{BC}$ interference screws in polymethyl methacrylate resin and p-values (Jonckheere-Terpstra trend test). There is a statistically significant difference between $7 \mathrm{~mm}$ screws and the two larger screw types. Statistically significant differences between $8 \mathrm{~mm}$ and $9 \mathrm{~mm} \mathrm{BC}$ screw could not be found

they noticed that the screw diameter had a significant effect on failure torque.

Weiler et al. [30] determined maximal torque at failure for bioabsorbable interference screws between $2.30 \pm$ $0.10 \mathrm{Nm}$ (8 mm poly-(glycolide-co-trimethylene-carbonate)) and $9.06 \pm 0.68 \mathrm{Nm}(7 \mathrm{~mm}$ poly-(D, L-lactide)). They also found that the torsional stability is highly depending on the drive design. In a cadaver study Kohn and Rose [43], investigated the influence of screw diameter and insertion torque on primary stability. They found that tibial fixation using $9 \mathrm{~mm}$ screws was significantly stronger than tibial fixation using $7 \mathrm{~mm}$ screws. Comparing the results of the present study to the values Costi et al. [32] acquired, we demonstrated that the $\mathrm{BC}$ screws have a torsional stability equal to that of most bioabsorbable screws. Especially the $8 \mathrm{~mm} \mathrm{BC}$ screw with a hexagonal head and the $9 \mathrm{~mm}$ screw were stronger than most bioabsorbable screws. Comparing the results of the present study to those reported by Weiler et al. [30] the stability of the $\mathrm{BC}$ screws appeared to be lower than that of the bioabsorbable interference screws tested. A possible explanation for the lower breaking torques of the $\mathrm{BC}$ screws in the present study is that in the experimental setup of Weiler et al. [30] the screws protruded only 1 $\mathrm{mm}$ from the polyurethane. Additionally the use of polymethyl methacrylate resin in the present study might be a reason for the lower stability. During the hardening of polymethyl methacrylate, higher temperatures arise than with polyurethane resin [30]. This can cause a change of shape as well as destabilisation of the $\mathrm{BC}$ screws.

Bovine compact bone interference screws as well as bioabsorbable interference screws [44] can break off during screwing in. This usually happens in the final phase of screw insertion, when the highest torque values are reached. Piltz et al. [45] determined a mean insertion torque of $1.6 \pm 1.1 \mathrm{Nm}$ for BPTB graft fixation at the tibial channel with bioabsorbable interference screws $(8 \mathrm{~mm}$ 
poly-L-lactide). In the results of other studies, values from $0.30 \pm 0.19$ to $0.60 \pm 0.30 \mathrm{Nm}(7 \mathrm{~mm}$ poly-(L-lactide)) [18] and from $0.71 \pm 0.14 \mathrm{Nm}(9 \mathrm{~mm}$ poly-(D, Llactide co-glycolide)) to $2.45 \pm 0.66 \mathrm{Nm}$ (8 mm poly-(Llactide)) [30] are reported. In the present study a mean insertion torque of $1.83 \pm 0.76 \mathrm{Nm}$ was applied for the 8 $\mathrm{mm} \mathrm{BC}$ screw. The self-made BC screws showed a good torsional stability and were able to withstand the usual intraoperative loads. Biomechanical studies can provide insight into the torsional stability of interference screws with different diameters and designs. However, conclusions about clinical applications are difficult to draw, as in vivo additional bending and shear forces act upon the screws. Furthermore, the results of biomechanical studies depend on a variety of factors such as bone quality, tissue species (human, xenogeneic) and screw design, size and material [30]. Therefore, a direct comparison of the study models in the literature is possible only to a certain extent. However, the constant experimental conditions allow a comparison of the fixation elements' performance in each test model.

We observed one $\mathrm{BC}$ screw breakage at the end of the insertion in the graft tunnel in porcine test specimens. In most cases bioabsorbable screws have screwdriver holes that run the entire length of the screw, thus when breakage occurs in many cases the whole screw is damaged by splitting [32]. The BC screws have an external head for the screw driver that functions as a predetermined breaking point. The screw head breaks off under maximal load usually at the end of the insertion. In order to reduce the number of screw breakages, the load transfer between screw driver and screw should be improved in future design modifications. Due to the fact that $\mathrm{BC}$ screws are not cannulated, the risk of malpositioning is increased. Although it is technically possible to produce cannulated bone screws, early tests showed them to be too fragile.

The BC screws had a longer non-threaded tip in order to minimise diversity and provide a standardised, reproducible placement. In other biomechanical studies non-cannulated screws were examined and were implanted in the same way [30].

Despite the good clinical results of the BPTВ [46] and soft tissue interference screw fixation [47] complications have been reported. Screw thread laceration of the bone plug, the tendon itself or the graft traction sutures are clinically important and may be reasons for failure $[48,49]$. Particularly, there are concerns about the soft tissue graft damage by the screw threads. Zantop et al. [50] could show by direct comparison of bioabsorbable and titanium interference screws, that graft damage was significantly higher in the titanium interference group. This is due to the fact that titanium screws had sharp thread edges. In theory, it is possible to minimise graft damage by using interference screws with rounded thread edges. The thread edges of both the BC and the Tutofix are rounded, but it is not possible to conclude from the present study, if rounded thread edges still can cause transplant damage.

The ideal interference screw material should be replaced by cancellous autologous bone. In a prospective study by Tecklenburg et al. [51], BPTB grafts were used in 40 patients for ACL reconstruction. Tibial fixation was carried out with two conventional bioabsorbable interference screws (poly-(L-lactide/hydroxyapatite)) and poly(L-lactide/ $\beta$-tricalcium phosphate)) and with an allogeneic interference screw. After a follow-up of 24 months there were no significant differences between the different screws regarding the subjective and the clinical results. MRI showed that only the allogeneic screws were incorporated completely. Complete incorporation of xenogeneic materials was proven by different authors $[23,52]$. The microstructure of xenogeneic bone resembles that of human bone [53]. There is no difference between bovine and human material regarding osteoblast proliferation on dehydrated cancellous bone slices [54]. However, some possible problems concerning xenogeneic implants like immune reaction must be taken into account and have to be investigated in further studies. In theory, cellular components are removed from the implants by validated sterilisation methods [55]. The bovine spongiform encephalopathy (BSE) has shown that it is possible that previously unknown pathogenic agents like prions are not inactivated completely by conventional methods.

A possible methodical weakness of the present study may be the manual screw turning. If the experiment is performed inappropriately, high bending moments arise by the screw driver. To minimise disturbing factors like this, all experiments were carried out by the same person, and attention was paid that a constant axial loading without bending was applied. The manual turning, however, corresponds to the in vivo situation during surgery, where the mentioned bending moments can occur in the same way. A further drawback of our study is the low number of screws tested. In comparative studies, the number of screws tested is equally $[30,56]$ or slightly higher [32]. The small number of tested screws does not allow a general conclusion about the biomechanical properties of interference screws derived from bovine compact bone. Bigger numbers might have been preferable. Nevertheless, the results presented in this study might serve for later projects with this model.

The availability of young human knees for test models is often limited. Therefore, it is reasonable under experimental aspects to use porcine test specimens, because porcine knee joints resemble the human knee joint anatomically [57] and are a well acknowledged animal model [13]. It could be shown that the average bone density in the proximal porcine tibia was similar as in the proximal 
tibia of young human bone [58]. Brown et al. [59] noticed that animal specimens are more appropriate for studies than specimens from older humans.

The search for an ideal interference screw material for ACL graft fixation is still on-going. The material should be incorporated completely and be replaced fully by endogenous cancellous bone. This would also be helpful in revision cases where sometimes due to bone resorption two operations are necessary.

\section{Conclusion}

The results of the present study showed no significant differences regarding the torsional stability between the three different $8 \mathrm{~mm}$ interference screws. A larger screw diameter significantly lead to higher torsion stability. Further improvement of the design of the screws and the instruments should also improve the biomechanical properties of BC screws. The safety and in vivo performance of products derived from xenogeneic bone should be the focus of further investigations.

\section{Competing interests}

The authors declare that they have no competing interests.

\section{Authors' contributions}

Each author has made substantial intellectual contributions to this study: JB: performed the experiments, drafted the manuscript; TE: performed the experiments, drafted and revised the manuscript; SH and NT: performed the statistical analysis; LG: initiated the study, and participated in its design and coordination; BFE, JS, MDS: participated in analysis and interpretation of data. All authors read and approved the final manuscript.

\section{Acknowledgements}

The authors wish to thank Dr Johanna Schmitt for translating the manuscript into English.

\section{Author Details}

'Department of Orthopaedics and Rheumatology, University Hospital Marburg, Baldingerstrasse, 35043 Marburg, Germany, ${ }^{2}$ Department of Orthopaedics, Gotenstrasse 1-6, 65929 Frankfurt/Main, Germany, ${ }^{3}$ Department of Trauma, Hand and Reconstructive Surgery, University Hospital Marburg, Baldingerstrasse, 35043 Marburg, Germany and ${ }^{4}$ Institute of Medical Biometry and Epidemiology, Philipps-University Marburg, Bunsenstrasse 3, 35037 Marburg, Germany

Received: 1 November 2009 Accepted: 1 May 2010

Published: 1 May 2010

\section{References}

1. Majewski M, Susanne H, Klaus S: Epidemiology of athletic knee injuries: A 10-year study. Knee 2006, 13(3):184-188.

2. Krudwig W: Current situation of arthroscopy in Germany. Arthroskopie 2000, 13:191-193.

3. Weiler A, Scheffler S, Hoher J: [Transplant selection for primary replacement of the anterior cruciate ligament]. Orthopade 2002, 31(8):731-740

4. Abate JA, Fadale PD, Hulstyn MJ, Walsh WR: Initial fixation strength of polylactic acid interference screws in anterior cruciate ligament reconstruction. Arthroscopy 1998, 14(3):278-284.

5. Pinczewski LA, Lyman J, Salmon LJ, Russell VJ, Roe J, Linklater J: A 10-year comparison of anterior cruciate ligament reconstructions with hamstring tendon and patellar tendon autograft: a controlled, prospective trial. Am J Sports Med 2007, 35(4):564-574.

6. Shelbourne KD, Nitz P: Accelerated rehabilitation after anterior cruciate ligament reconstruction. Am J Sports Med 1990, 18(3):292-299.
7. Milano G, Mulas PD, Ziranu F, Piras S, Manunta A, Fabbriciani C Comparison between different femoral fixation devices for $\mathrm{ACL}$ reconstruction with doubled hamstring tendon graft: a biomechanical analysis. Arthroscopy 2006, 22(6):660-668.

8. Vuori I, Heinonen A, Sievanen H, Kannus P, Pasanen M, Oja P: Effects of unilateral strength training and detraining on bone mineral density and content in young women: a study of mechanical loading and deloading on human bones. Calcif Tissue Int 1994, 55(1):59-67.

9. $\mathrm{Fu} F \mathrm{FH}$, Bennett $\mathrm{CH}$, Lattermann C, Ma CB: Current trends in anterior cruciate ligament reconstruction. Part 1: Biology and biomechanics of reconstruction. Am J Sports Med 1999, 27(6):821-830.

10. Ishibashi Y, Toh S, Okamura Y, Sasaki T, Kusumi T: Graft incorporation within the tibial bone tunnel after anterior cruciate ligament reconstruction with bone-patellar tendon-bone autograft. Am J Sports Med 2001, 29(4):473-479.

11. Laxdal G, Kartus J, Ejerhed L, Sernert N, Magnusson L, Faxen E, Karlsson J: Outcome and risk factors after anterior cruciate ligament reconstruction: a follow-up study of 948 patients. Arthroscopy 2005 , 21(8):958-964

12. Duquin TR, Wind WM, Fineberg MS, Smolinski RJ, Buyea CM: Current trends in anterior cruciate ligament reconstruction. J Knee Surg 2009, 22(1):7-12.

13. Seil R, Rupp S, Krauss PW, Benz A, Kohn DM: Comparison of initial fixation strength between biodegradable and metallic interference screws and a press-fit fixation technique in a porcine model. Am J Sports Med 1998, 26(6):815-819.

14. George MS, Dunn WR, Spindler KP: Current concepts review: revision anterior cruciate ligament reconstruction. Am J Sports Med 2006, 34(12):2026-2037.

15. Suh JS, Jeong EK, Shin KH, Cho JH, Na JB, Kim DH, Han CD: Minimizing artifacts caused by metallic implants at MR imaging: experimental and clinical studies. AJR Am J Roentgeno/ 1998, 171(5):1207-1213.

16. Drogset JO, Grontvedt T, Myhr G: Magnetic resonance imaging analysis of bioabsorbable interference screws used for fixation of bone-patellar tendon-bone autografts in endoscopic reconstruction of the anterior cruciate ligament. Am J Sports Med 2006, 34(7):1164-1169.

17. Macarini L, Murrone M, Marini S, Mocci A, Ettorre GC: [MRI in ACL reconstructive surgery with PDLLA bioabsorbable interference screws: evaluation of degradation and osteointegration processes of bioabsorbable screws]. Radiol Med 2004, 107(1-2):47-57.

18. Pena F, Grontvedt T, Brown GA, Aune AK, Engebretsen L: Comparison of failure strength between metallic and absorbable interference screws. Influence of insertion torque, tunnel-bone block gap, bone mineral density, and interference. Am J Sports Med 1996, 24(3):329-334.

19. Baums MH, Zelle BA, Schultz W, Ernstberger T, Klinger HM: Intraarticular migration of a broken biodegradable interference screw after anterior cruciate ligament reconstruction. Knee Surg Sports Traumatol Arthrosc 2006, 14(9):865-868

20. Hall MP, Hergan DM, Sherman OH: Early fracture of a bioabsorbable tibial interference screw after $A C L$ reconstruction with subsequent chondral injury. Orthopedics 2009, 32(3):208.

21. Zheng N, Price $C T$, Indelicato PA, Gao B: Tibial fixation of bone-patellar tendon-bone grafts in anterior cruciate ligament reconstruction: a cadaveric study of bovine bone screw and biodegradable interference screw. Am J Sports Med 2008, 36(12):2322-2327.

22. Adeyemo WL, Reuther T, Bloch W, Korkmaz Y, Fischer JH, Zoller JE, Kuebler $A C$ : Healing of onlay mandibular bone grafts covered with collagen membrane or bovine bone substitutes: a microscopical and immunohistochemical study in the sheep. Int J Oral Maxillofac Surg 2008, 37(7):651-659.

23. Rosito R, Galia CR, Macedo CA, Moreira LF, Quaresma LM, Palma HM: Acetabular reconstruction with human and bovine freeze-dried bone grafts and a reinforcement device. Clinics (Sao Paulo) 2008, 63(4):509-514.

24. Beevers DJ: Metal vs bioabsorbable interference screws: initial fixation. Proc Inst Mech Eng H 2003, 217(1):59-75.

25. Ilahi OA, Nolla JM, Ho DM: Intra-tunnel fixation versus extra-tunnel fixation of hamstring anterior cruciate ligament reconstruction: a meta-analysis. J Knee Surg 2009, 22(2):120-129.

26. Johnson LL, vanDyk GE: Metal and biodegradable interference screws: comparison of failure strength. Arthroscopy 1996, 12(4):452-456. 
27. Kocabey Y, Klein S, Nyland J, Caborn D: Tibial fixation comparison of semitendinosus-bone composite allografts fixed with bioabsorbable screws and bone-patella tendon-bone grafts fixed with titanium screws. Knee Surg Sports Traumatol Arthrosc 2004, 12(2):88-93.

28. Park DK, Fogel HA, Bhatia S, Bach BR Jr, Gupta A, Shewman EF, Wang V Verma N, Provencher MT: Tibial fixation of anterior cruciate ligament allograft tendons: comparison of 1-, 2-, and 4-stranded constructs. Am J Sports Med 2009, 37(8):1531-1538.

29. Walsh MP, Wijdicks CA, Parker JB, Hapa O, LaPrade RF: A comparison between a retrograde interference screw, suture button, and combined fixation on the tibial side in an all-inside anterior cruciate ligament reconstruction: a biomechanical study in a porcine model. Am J Sports Med 2009, 37(1):160-167

30. Weiler A, Windhagen HJ, Raschke MJ, Laumeyer A, Hoffmann RF: Biodegradable interference screw fixation exhibits pull-out force and stiffness similar to titanium screws. Am J Sports Med 1998, 26(1):119-126.

31. Zantop T, Ruemmler M, Welbers B, Langer M, Weimann A, Petersen W: Cyclic loading comparison between biodegradable interference screw fixation and biodegradable double cross-pin fixation of human bonepatellar tendon-bone grafts. Arthroscopy 2005, 21(8):934-941.

32. Costi JJ, Kelly AJ, Hearn TC, Martin DK: Comparison of torsional strengths of bioabsorbable screws for anterior cruciate ligament reconstruction. Am J Sports Med 2001, 29(5):575-580.

33. Nyland J, Kocabey Y, Caborn DN: Insertion torque pullout strength relationship of soft tissue tendon graft tibia tunnel fixation with a bioabsorbable interference screw. Arthroscopy 2004, 20(4):379-384.

34. Phillips BB, Cain EL, Dlabach JA, Azar FM: Correlation of interference screw insertion torque with depth of placement in the tibial tunnel using a quadrupled semitendinosus-gracilis graft in anterior cruciate ligament reconstruction. Arthroscopy 2004, 20(10):1026-1029.

35. Boccafoschi F, Bosetti MMC: Evaluation of bioresorbable implants from bovine bone: in vitro preliminary observations. J App/Biomat Biomech 2005, 3:34-41.

36. Hofmann C, Schadel-Hopfner M, Berns T, Sitter H, Gotzen L: [Influence of processing and sterilization on the mechanical properties of pins made from bovine cortical bone]. Unfallchirurg 2003, 106(6):478-482.

37. Pfuhler ST, Poth AMH: Cell growth analysis via BCA-staining with an extract of tutoplast processed compact bovine bone-sterile. BSL Bioservice Project Report 1999, No.:990325. 1999.

38. Caborn DN, Urban WP Jr, Johnson DL, Nyland J, Pienkowski D: Biomechanical comparison between BioScrew and titanium alloy interference screws for bone-patellar tendon-bone graft fixation in anterior cruciate ligament reconstruction. Arthroscopy 1997, 13(2):229-232.

39. Kurosaka M, Yoshiya S, Andrish JT: A biomechanical comparison of different surgical techniques of graft fixation in anterior cruciate ligament reconstruction. Am J Sports Med 1987, 15(3):225-229.

40. Matthews LS, Lawrence SJ, Yahiro MA, Sinclair MR: Fixation strengths of patellar tendon-bone grafts. Arthroscopy 1993, 9(1):76-81.

41. Novak PJ, Bach BR Jr, Bush-Joseph CA, Badrinath S: Cost containment: a charge comparison of anterior cruciate ligament reconstruction. Arthroscopy 1996, 12(2):160-164

42. Rupp S, Seil R, Schneider A, Kohn D: Ligament graft initial fixation strength using biodegradable interference screws. J Biomed Mater Res 1996, 48(1):70-76.

43. Kohn D, Rose C: Primary stability of interference screw fixation. Influence of screw diameter and insertion torque. Am J Sports Med 1994, 22(3):334-338.

44. Maletis GB, Cameron SL, Tengan JJ, Burchette RJ: A prospective randomized study of anterior cruciate ligament reconstruction: a comparison of patellar tendon and quadruple-strand semitendinosus/ gracilis tendons fixed with bioabsorbable interference screws. Am J Sports Med 2007, 35(3):384-394.

45. Piltz S, Strunk P, Meyer L, Plitz W, Lob G: Fixation strength of a novel bioabsorbable expansion bolt for patellar tendon bone graft fixation: an experimental study in calf tibial bone. Knee Surg Sports Traumatol Arthrosc 2004, 12(5):376-383.

46. Corry IS, Webb JM, Clingeleffer AJ, Pinczewski LA: Arthroscopic reconstruction of the anterior cruciate ligament. A comparison of patellar tendon autograft and four-strand hamstring tendon autograft. Am J Sports Med 1999, 27(4):444-454.
47. Pinczewski LA, Deehan DJ, Salmon LJ, Russell VJ, Clingeleffer A: A five-year comparison of patellar tendon versus four-strand hamstring tendon autograft for arthroscopic reconstruction of the anterior cruciate ligament. Am J Sports Med 2002, 30(4):523-536.

48. Matthews LS, Soffer SR: Pitfalls in the use of interference screws for anterior cruciate ligament reconstruction: brief report. Arthroscopy 1989, 5(3):225-226.

49. Shen PH, Lien SB, Shen HC, Wang CC, Huang GS, Chao KH, Lee CH, Lin LC: Comparison of different sizes of bioabsorbable interference screws for anterior cruciate ligament reconstruction using bioabsorbable bead augmentation in a porcine model. Arthroscopy 2009, 25(10):1101-1107.

50. Zantop T, Weimann A, Schmidtko R, Herbort M, Raschke MJ, Petersen W: Graft laceration and pullout strength of soft-tissue anterior cruciate ligament reconstruction: in vitro study comparing titanium, poly-d, Ilactide, and poly-d, I-lactide-tricalcium phosphate screws. Arthroscopy 2006, 22(11):1204-1210.

51. Tecklenburg K, Burkart P, Hoser C, Rieger M, Fink C: Prospective evaluation of patellar tendon graft fixation in anterior cruciate ligament reconstruction comparing composite bioabsorbable and allograft interference screws. Arthroscopy 2006, 22(9):993-999.

52. Wander KW, Schwarz PD, James SP, Powers BE, Taylor B, Wimsatt JH: Fracture healing after stabilization with intramedullary xenograft cortical bone pins: a study in pigeons. Vet Surg 2000, 29(3):237-244.

53. Worth A, Mucalo M, Horne G, Bruce W, Burbidge $\mathrm{H}$ : The evaluation of processed cancellous bovine bone as a bone graft substitute. Clin Oral Implants Res 2005, 16(3):379-386.

54. Trentz OA, Hoerstrup SP, Sun LK, Bestmann L, Platz A, Trentz OL: Osteoblasts response to allogenic and xenogenic solvent dehydrated cancellous bone in vitro. Biomaterials 2003, 24(20):3417-3426.

55. Katz J, Mukherjee N, Cobb RR, Bursac P, York-Ely A: Incorporation and immunogenicity of cleaned bovine bone in a sheep model. J Biomater Appl 2009, 24(2):159-174.

56. Hunt $P$, Unterhauser FN, Strobel MJ, Weiler A: Development of a perforated biodegradable interference screw. Arthroscopy 2005 21(3):258-265.

57. Beynnon $B D, A$ mis $A A$ : In vitro testing protocols for the cruciate ligaments and ligament reconstructions. Knee Surg Sports Traumatol Arthrosc 1998, 6(Suppl 1):S70-76.

58. Nagarkatti DG, McKeon BP, Donahue BS, Fulkerson JP: Mechanical evaluation of a soft tissue interference screw in free tendon anterior cruciate ligament graft fixation. Am J Sports Med 2001, 29(1):67-71.

59. Brown CH Jr, Hecker AT, Hipp JA, Myers ER, Hayes WC: The biomechanics of interference screw fixation of patellar tendon anterior cruciate ligament grafts. Am J Sports Med 1993, 21(6):880-886.

Pre-publication history

The pre-publication history for this paper can be accessed here: http://www.biomedcentral.com/1471-2474/11/82/prepub

doi: $10.1186 / 1471-2474-11-82$

Cite this article as: Bauer et al., Torsional stability of interference screws derived from bovine bone - a biomechanical study BMC Musculoskeletal Disorders $2010,11: 82$ 